\title{
Development and Optimization of Osmotically Controlled Asymmetric Membrane Capsules for Delivery of Solid Dispersion of Lycopene
}

\author{
Nitin Jain, Rashmi Sareen, Neeraj Mahindroo, and K. L. Dhar \\ School of Pharmaceutical Sciences, Shoolini University, Bajhol, Solan, Himachal Pradesh 173229, India \\ Correspondence should be addressed to Rashmi Sareen; sareenrashmi@gmail.com
}

Received 29 August 2013; Accepted 19 December 2013; Published 29 January 2014

Academic Editors: J. Ali and T. Hatano

Copyright (C) 2014 Nitin Jain et al. This is an open access article distributed under the Creative Commons Attribution License, which permits unrestricted use, distribution, and reproduction in any medium, provided the original work is properly cited.

\begin{abstract}
The aim of the present investigation is to develop and statistically optimize the osmotically controlled asymmetric membrane capsules of solid dispersion of lycopene. Solid dispersions of lycopene with $\beta$-cyclodextrin in different ratios were prepared using solvent evaporation method. Solubility studies showed that the solid dispersion with 1:5 (lycopene: $\beta$-cyclodextrin) exhibited optimum solubility $(56.25 \mathrm{mg} / \mathrm{mL}$ ) for osmotic controlled delivery. Asymmetric membrane capsules (AMCs) were prepared on glass mold pins via dip coating method. Membrane characterization by scanning electron microscopy showed inner porous region and outer dense region. Central composite design response surface methodology was applied for the optimization of AMCs. The independent variables were ethyl cellulose $\left(X_{1}\right)$, glycerol $\left(X_{2}\right)$, and $\mathrm{NaCl}\left(X_{3}\right)$ which were varied at different levels to analyze the effect on dependent variables (percentage of cumulative drug release $\left(Y_{1}\right)$ and correlation coefficient of drug release $\left(Y_{2}\right)$ ). The effect of independent variables on the response was significantly influential. The $\mathrm{F}_{18}$ was selected as optimized formulation based on percentage of CDR (cumulative drug release) of $85.63 \%$ and correlation coefficient of 0.9994 . The optimized formulation was subjected to analyze the effect of osmotic pressure and agitational intensity on percentage of CDR. The drug release was independent of agitational intensity but was dependent on osmotic pressure of dissolution medium.
\end{abstract}

\section{Introduction}

The most important properties of oral drug delivery system are better patient compliance and ease of administration; due to this, oral delivery systems gain large share of market among various novel drug delivery technologies. For controlled delivery of drugs, the most efficient strategy available is osmotic devices based reliable drug delivery systems [1]. These types of systems work on the principle of osmosis. Osmotic pressure is generated by active material in itself or induced with the help of osmogen. When this system comes in contact with gastrointestinal tract, the fluid enters into the preparation and dissolves the active material in the core [2]. Thus the release of the solution is induced by the pressure created in the preparation at a slow but regular rate. The zero-order drug release kinetics of osmotic drug delivery system is independent on the chemical properties of the drug, physiological factors related to patients, or intake of food [ 3 ,
4], and it depends upon osmotic pressure of core components and formulation factors, including solubility of drug within the tablet core, characteristics of semipermeable membrane, and the size of orifice [5]. The asymmetric membrane capsule (AMC) consists of core containing drug material covered by an asymmetric membrane $[6,7]$. Higher rate of water influx is one of the main advantages of asymmetric membrane capsule allowing the drug release with lower osmotic pressures or lower solubilities [8]. Lycopene is one of the most common carotenoids found in serum of human being and the major one is in plasma $[9,10]$. Among various carotenoids, lycopene is the most potent antioxidant because of the presence of large number of conjugated double bonds [11]. However, high lipophilicity ( $\log P=17.64)$ of lycopene resulting in its extremely low aqueous solubility acts as barrier to its oral formulation and bioavailability [12].

This study aims to design and optimize osmotically controlled asymmetric membrane capsule of lycopene with 
TABLE 1: Experimental design for three factors and experimental values of responses.

\begin{tabular}{|c|c|c|c|c|c|}
\hline $\begin{array}{l}\text { Formulation } \\
\text { code }\end{array}$ & $\begin{array}{c}X_{1} \\
\text { (ethyl cellulose) } \\
\% \mathrm{w} / \mathrm{v}\end{array}$ & $\begin{array}{c}X_{2} \\
\text { (glycerol) } \\
\% \mathrm{w} / \mathrm{v}\end{array}$ & $\begin{array}{c}X_{3} \\
(\mathrm{NaCl}) \\
\mathrm{mg}\end{array}$ & $\begin{array}{c}Y_{1} \\
\text { (\% cumulative } \\
\text { drug Release) }\end{array}$ & $\begin{array}{c}Y_{2} \\
\text { (correlation } \\
\text { coefficient) }\end{array}$ \\
\hline $\mathrm{F}_{1}$ & 12.50 & 13.50 & 75.00 & 89.26 & 0.9923 \\
\hline $\mathrm{F}_{2}$ & 12.50 & 13.50 & 117.04 & 94.39 & 0.9825 \\
\hline $\mathrm{F}_{3}$ & 10.00 & 15.00 & 100.00 & 93.74 & 0.9245 \\
\hline $\mathrm{F}_{4}$ & 10.00 & 12.00 & 50.00 & 79.65 & 0.9820 \\
\hline $\mathrm{F}_{5}$ & 12.50 & 13.50 & 32.96 & 71.20 & 0.9714 \\
\hline $\mathrm{F}_{6}$ & 8.30 & 13.50 & 75.00 & 92.45 & 0.9526 \\
\hline $\mathrm{F}_{7}$ & 12.50 & 13.50 & 75.00 & 89.96 & 0.9918 \\
\hline $\mathrm{F}_{8}$ & 12.50 & 13.50 & 75.00 & 90.41 & 0.9921 \\
\hline $\mathrm{F}_{9}$ & 10.00 & 15.00 & 50.00 & 83.63 & 0.9245 \\
\hline $\mathrm{F}_{10}$ & 12.50 & 13.50 & 75.00 & 90.41 & 0.9951 \\
\hline $\mathrm{F}_{11}$ & 12.50 & 13.50 & 75.00 & 92.57 & 0.9829 \\
\hline $\mathrm{F}_{12}$ & 15.00 & 12.00 & 50.00 & 69.47 & 0.9975 \\
\hline $\mathrm{F}_{13}$ & 16.70 & 13.50 & 75.00 & 74.11 & 0.9986 \\
\hline $\mathrm{F}_{14}$ & 15.00 & 15.00 & 50.00 & 81.84 & 0.9842 \\
\hline $\mathrm{F}_{15}$ & 15.00 & 15.00 & 100.00 & 85.90 & 0.9198 \\
\hline $\mathrm{F}_{16}$ & 10.00 & 12.00 & 100.00 & 89.65 & 0.9185 \\
\hline $\mathrm{F}_{17}$ & 12.50 & 13.50 & 75.00 & 91.76 & 0.9914 \\
\hline $\mathrm{F}_{18}$ & 12.50 & 10.98 & 75.00 & 85.63 & 0.9994 \\
\hline $\mathrm{F}_{19}$ & 15.00 & 12.00 & 100.00 & 75.26 & 0.9982 \\
\hline $\mathrm{F}_{20}$ & 12.50 & 16.02 & 75.00 & 90.32 & 0.9725 \\
\hline
\end{tabular}

enhanced solubility by forming solid dispersion with $\beta$ cyclodextrin. A three-factor central composite design (CCD) was used to optimize formulations of asymmetric membrane capsules containing solid dispersion of lycopene. The effect of osmotic pressure and agitational intensity on drug release has also been examined in this work.

\section{Materials and Methods}

2.1. Materials. Lycopene was obtained as gift sample from Alpha Remedies, Ambala, India. Ethyl cellulose, sodium chloride, and glycerol were procured from S.D. fine chemicals, Mumbai, India. Ethanol, acetone, and glycerol were procured from Nice Chemicals, New Delhi. All the chemicals and solvents used were of analytical grade.

2.2. Solubility Studies. The release kinetics of drug through osmotic controlled systems is directly related to the solubility of the drug within the formulation. Therefore, the solubility of the drug in various dissolution media was assessed by taking excess amount of drug in double distilled water ( $\mathrm{pH}$ 6.8), $0.1 \mathrm{~N} \mathrm{HCl}$ ( $\mathrm{pH} \mathrm{1.2)}$, and phosphate buffer ( $\mathrm{pH} 7.4$ ) in orbital solubility shaker (Inco, India) at $37^{\circ} \pm 0.5^{\circ} \mathrm{C}$ [13]. Excess amounts were taken to ensure saturation and all the solutions were equilibrated for $72 \mathrm{~h}$. After $72 \mathrm{~h}$ saturated solutions were filtered, and after suitable dilutions the concentration of drug was determined at $472 \mathrm{~nm}$ using a double beam UV spectrophotometer (Shimadzu 1700, Japan).

2.3. Solid Dispersion of Lycopene. Solid dispersions of lycopene with $\beta$-cyclodextrin were prepared by solvent evaporation method. Lycopene and $\beta$-cyclodextrin were varied in different ratios $(1: 1$ to $1: 5)$ to achieve the desired solubility. Accurately weighed quantities of the drug and the polymer were separately dissolved in ethanol and the solutions were mixed together after solubilization and then sonicated for $30 \mathrm{~min}$ [14]. The solutions were maintained at $40^{\circ} \mathrm{C}$ for $4 \mathrm{~h}$ followed by lyophilization and then the solid dispersions were also assessed for solubility.

2.4. Fabrication of Asymmetric Membrane Capsule. The asymmetric membrane capsules (AMCs) were fabricated based on central composite design (Table 1). Dip coating method was used for the preparation of AMCs. The glass mold pins (diameter $5.92 \pm 0.07$ for body and $6.46 \pm 0.05$ for 
the cap) were dipped in polymeric solution of ethyl cellulose $(10 \% \mathrm{w} / \mathrm{v}$ and $15 \% \mathrm{w} / \mathrm{v})$ and glycerol $(12 \% \mathrm{w} / \mathrm{v}$ and $15 \% \mathrm{w} / \mathrm{v})$ dissolved in mixture of ethanol and acetone. The mold pins were allowed to dip in polymeric solution for $20 \mathrm{~s}$. After $20 \mathrm{~s}$ the glass mold pins were removed from the polymeric solution and were quenched in aqueous solution of glycerol $(10 \% \mathrm{w} / \mathrm{v})$ for $10 \mathrm{~min}$. After quenching the AMCs were dried for $10 \mathrm{~s}$ and then trimmed off for appropriate size from the mold pins. The AMCs were filled manually with lycopene solid dispersion (LSD) and sodium chloride after uniformly mixed in polythene bag. The AMCs were sealed with $10 \% \mathrm{w} / \mathrm{v}$ solution of ethanol in acetone and water.

2.5. Characterization of AMCs. The asymmetric membrane capsules were analyzed for physical appearance and geometric dimensions and compared with conventional gelatin capsules.

2.5.1. Scanning Electron Microscopy. AMCs were examined for their asymmetric structure using SEM (QUANTA 250, FEI Makers, Singapore). The asymmetric membrane surfaces (inner and outer) were sputter coated for 5-10 min with gold by using fine coat ion sputter and examined under SEM [15].

2.5.2. In Vitro Drug Release. In vitro release studies were performed for developed AMCs to evaluate the effect of various formulation parameters on the release rate of the drug. Dissolution was performed in USP-II dissolution apparatus (Electrolab EDT-LX 08, Mumbai) at $37^{\circ} \pm 0.5^{\circ} \mathrm{C}$ and $100 \mathrm{rpm}$ for $12 \mathrm{~h}$. The dissolution fluid simulated gastric fluid (SGF) ( $\mathrm{pH}$ 1.2) for first two hours and simulated intestinal fluid (SIF) ( $\mathrm{pH} 7.4)$ for subsequent hours [16]. Sample $(5 \mathrm{~mL})$ was withdrawn periodically and replaced with preheated $\left(37^{\circ} \pm\right.$ $0.5^{\circ} \mathrm{C}$ ) fresh medium. The samples were analyzed by $\mathrm{UV}$ spectrophotometer (Shimadzu 1700) at $472 \mathrm{~nm}$.

2.6. Optimization Study. The effect of independent variables such as concentration of ethyl cellulose $\left(X_{1}\right)$, glycerol $\left(X_{2}\right)$, and sodium chloride $\left(X_{3}\right)$ was analyzed by using central composite design. The responses selected for the study were (i) percentage of in vitro cumulative drug release $\left(Y_{1}\right)$, because formulations were designed to release the drug up to $12 \mathrm{~h}$ and (ii) correlation coefficient of drug release $\left(r^{2}\right)$ as formulations were expected to follow zero order release. The experiments were modeled by Design Expert 8.0.5.2 software (Stat-Ease, Inc., Minneapolis, USA). The layout for central composite design is given in Table 1 . The selection of optimized formulation was based on maximum values of $Y_{1}$ and $Y_{2}$. Further the optimized formulation was subjected to analyze the effect of osmotic pressure and agitational intensity on drug release.

2.7. Effect of Osmotic Pressure on Drug Release. The release of drug from AMC depends upon osmotic pressure and osmotic agent present inside the formulation. Release studies of the optimized formulation were performed in the media of different osmotic pressure for the assessment of the mechanism of lycopene release. Sodium chloride (osmotically active solute)
TABLE 2: Solubility study of solid dispersions of lycopene.

\begin{tabular}{lc}
\hline Lycopene $: \beta$-cyclodextrin & Solubility $(\mathrm{mg} / \mathrm{mL})$ \\
\hline $1: 1$ & $9.29 \pm 1.06$ \\
$1: 2$ & $22.68 \pm 0.72$ \\
$1: 3$ & $30.19 \pm 0.84$ \\
$1: 4$ & $39.78 \pm 2.49$ \\
$1: 5$ & $56.25 \pm 1.26$ \\
\hline
\end{tabular}

was used to vary the osmotic pressure of the dissolution medium (SIF) and the $\mathrm{pH}$ was adjusted to $7.4 \pm 0.5$. In these studies formulation contained (i) $100 \mathrm{mg}$ of $\mathrm{NaCl}$ inside and $0 \mathrm{mg}$ outside (dissolution medium) and (ii) $100 \mathrm{mg}$ of $\mathrm{NaCl}$ inside and $50 \mathrm{mg}$ outside. All the studies were performed in $900 \mathrm{~mL}$ of medium using USP-II dissolution apparatus at $100 \mathrm{rpm}$.

2.8. Effect of Agitational Intensity on Drug Release. This study was carried out in a view to analyze the effect of GI motility on the drug release. Release studies of the optimized formulation were carried out in USP-II dissolution apparatus at different $\mathrm{rpm}(50,100$, and 150), in order to study the effect of agitational intensity on the release of the drug from the AMC. Samples were withdrawn at predetermined intervals and analyzed by UV spectrophotometer at $472 \mathrm{~nm}$.

\section{Results and Discussion}

3.1. Solubility Studies. The solubility of lycopene in different medium was $0.1 \mathrm{~N} \mathrm{HCl}\left(2.23 \times 10^{-3} \mathrm{~g} / \mathrm{cm}^{3}\right)$, double distilled water $\left(3.07 \times 10^{-3} \mathrm{~g} / \mathrm{cm}^{3}\right)$, and phosphate buffer $(3.73 \times$ $10^{-3} \mathrm{~g} / \mathrm{cm}^{3}$ ). Low solubility of lycopene indicated the need of solubility enhancement, as with low solubility the release of drug from the AMC would be erratic.

3.2. Solid Dispersion of Lycopene. The solid dispersions of lycopene with $\beta$-cyclodextrin (LSDs) in different ratios (1:1 to $1: 5)$ were successfully prepared by solvent evaporation method. The solubility study of solid dispersion revealed enhanced solubility of drug. The LSD with 1:5 (drug : polymer) showed solubility of $56.25 \mathrm{mg} / \mathrm{mL}$ (Table 2) and was selected for AMC since for osmotic controlled delivery, the drug should have solubility in the range of 50$300 \mathrm{mg} / \mathrm{mL}$ [13].

3.3. Characterization of Asymmetric Membrane Capsule. As per the procedure stated above the AMCs (Figure 1) were prepared by dip coating method. AMCs were compared with conventional gelatin capsules (CGCs) for appearance and geometric characterization. AMCs showed higher opacity as compared to CGCs. Comparison of dimensions of AMCs revealed high degree of similarity with CGCs $(P<0.005)$ (Table 3). 
TABLE 3: Geometric and physical characterization of AMC* as compared to CGC* .

\begin{tabular}{|c|c|c|c|c|c|c|}
\hline \multirow{3}{*}{ Type of capsule } & \multirow{3}{*}{ Appearance } & \multicolumn{5}{|c|}{ Dimensions, $\mathrm{mm}$} \\
\hline & & \multicolumn{2}{|c|}{ Cap } & \multicolumn{2}{|c|}{ Body } & \multirow{2}{*}{ Sealed } \\
\hline & & Length & Diameter & Length & Diameter & \\
\hline CGC & Transparent & $9.25 \pm 0.18$ & $5.91 \pm 0.09$ & $15.98 \pm 0.15$ & $5.21 \pm 0.09$ & $20.15 \pm 0.08$ \\
\hline AMC & Opaque & $9.37 \pm 0.22$ & $6.02 \pm 0.11$ & $16.07 \pm 0.27$ & $5.37 \pm 0.13$ & $20.27 \pm 0.16$ \\
\hline
\end{tabular}

*AMC indicates asymmetric membrane capsule and CGC indicates conventional gelatin capsule.

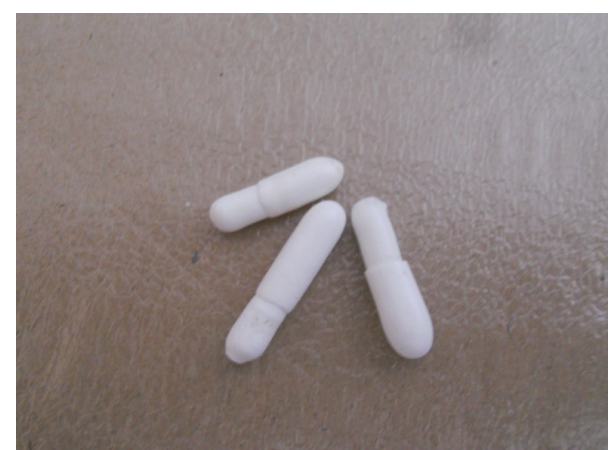

Figure 1: Photograph of asymmetric membrane capsules.

3.4. Scanning Electron Microscopy. SEM photomicrographs of developed AMCs showed outer dense region (Figure 2(a)) and inner porous region (Figure 2(b)). SEM photomicrographs revealed the asymmetric nature of capsules which is desirable for osmosis. The asymmetric nature of membrane may be due to incorporation of plasticizer (glycerol), which acted as pore former.

3.5. Optimization Study. The effect of independent variables over the dependent variables was assessed by using central composite design.

3.5.1. Influence of Independent Variables on Cumulative Percentage of Drug Release $\left(Y_{1}\right)$. The results of in vitro release suggested decrease in the release of drug with increase in the level of ethyl cellulose (EC) $\left(X_{1}\right)$. This may be due to the fact that with higher level of EC, the drug has to travel more path length. Due to this reason higher concentration of EC impedes the drug release (Figure 3(a)). Figure 3(c) demonstrated that release of drug from the system increased with the increase in level of glycerol. The reason may be that higher level of glycerol $\left(X_{2}\right)$ will result in more porous structure of inner layer of AMCs and higher porosity of inner surface resulted in higher drug release. $\mathrm{NaCl}\left(X_{3}\right)$ also affected the release rate in the manner that on increasing the level of $\mathrm{NaCl}$ the release rate was found to increase due to higher osmotic pumping effect caused by high concentration of osmogen (Figure 3(b)).

3.5.2. Influence of Independent Variables on Correlation Coefficient of Drug Release $\left(Y_{2}\right)$. The correlation coefficient was found to increase with increase in the level of $X_{1}$ as evident form Figure 4(a). Results suggested that increase in level of $X_{2}$ caused decrease in $Y_{2}$ (Figure $4(\mathrm{c})$ ). The reason behind this may be that the increase in level of $X_{2}$ resulted in more porous inner structure of AMC which resulted in irregular drug release. Figure 4(b) showed increase in $Y_{2}$ with increase in the level of $X_{3}$ which was followed by decrease in $Y_{2}$. This may be due to the reason that increase in level of $\mathrm{NaCl}$ provided adequate osmotic pressure making hydration of core of capsule and resulted in gentle release profile.

3.5.3. Selection of Optimized Formulation. The optimized formulation was selected on the basis of maximum value of percentage of cumulative drug release $\left(Y_{1}\right)$ and correlation coefficient of drug release $\left(Y_{2}\right) . \mathrm{F}_{18}$ was selected as optimized formulation having $85.63 \%$ of drug release and 0.9994 of correlation coefficient of drug. Further the $\mathrm{F}_{18}$ was subjected to analyze the effect of osmotic pressure and agitational intensity on in vitro drug release.

3.6. Effect of Osmotic Pressure on In Vitro Drug Release. Release studies of lycopene from AMC were performed to analyze mechanism of drug release. Results indicated that the release was highly dependent on osmotic pressure of release medium. Lycopene release from AMC with $100 \mathrm{mg}$ of $\mathrm{NaCl}$ inside and $0 \mathrm{mg}$ outside showed controlled release due to creation of molar environment by osmogen $(\mathrm{NaCl})$. The AMC with $100 \mathrm{mg}$ of $\mathrm{NaCl}$ inside and $50 \mathrm{mg}$ outside exhibited slow release with plateau reaching in the sixth hour (Figure 5). This was may be due to the decreased osmotic gradient. All the results suggested osmotic pumping as a primary mechanism of drug release from AMC.

\subsection{Effect of Agitational Intensity on In Vitro Drug Release.} Figure 6 showed the release of lycopene from AMC at three different $\mathrm{rpm}(50,100$, and 150). It can be seen that the lycopene release from AMC was independent of agitational intensity of dissolution media as there was nonsignificant difference in release of drug at different $\operatorname{rpm}(P<0.01$, $\left.f_{2}=98.17\right)$.

\section{Conclusion}

Asymmetric membrane capsule for the solid dispersion of lycopene with $\beta$-cyclodextrin was successfully developed using dip coating method and optimized using central 


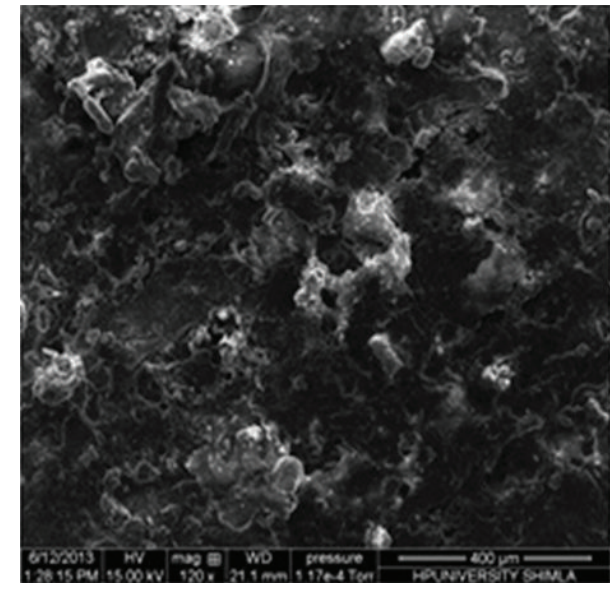

(a)

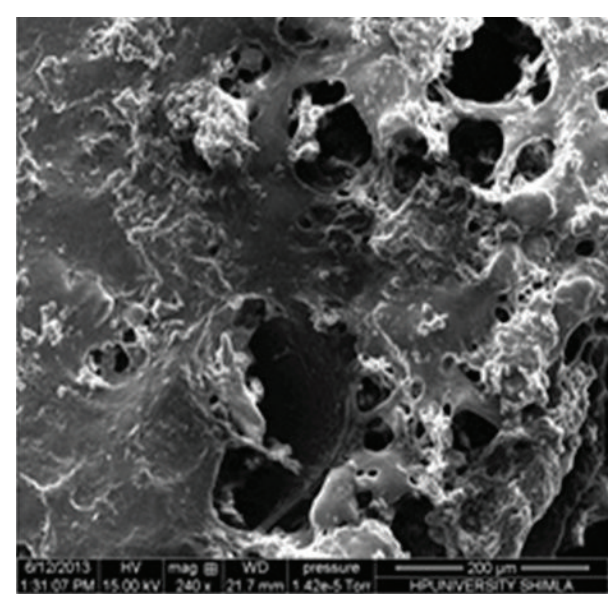

(b)

FIGURE 2: SEM photomicrographs of (a) outer surface and (b) inner surface of AMC.

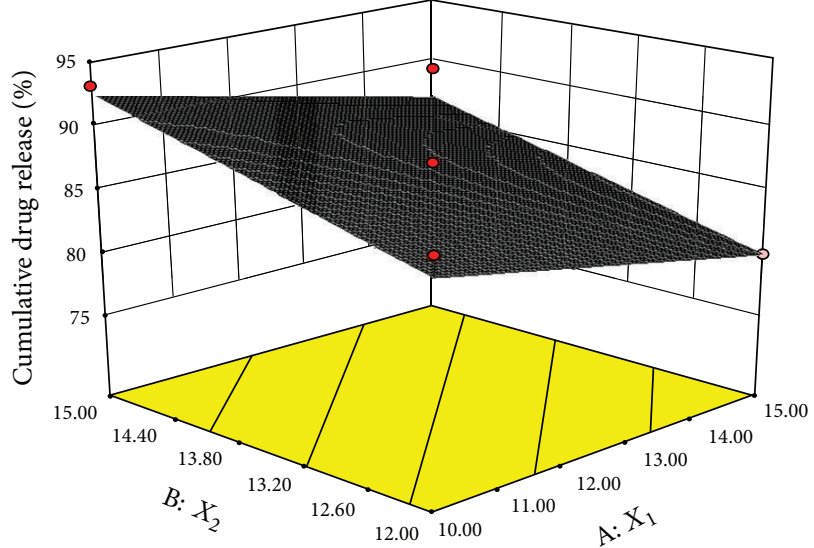

(a)

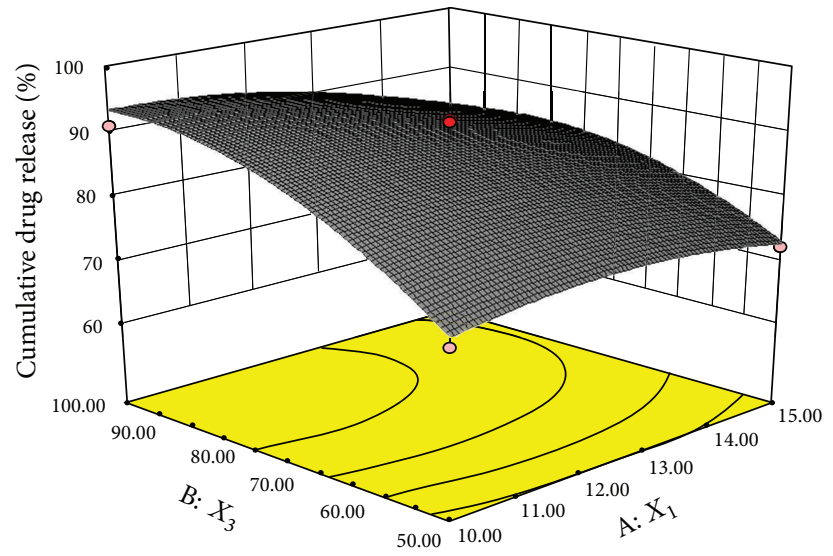

(b)

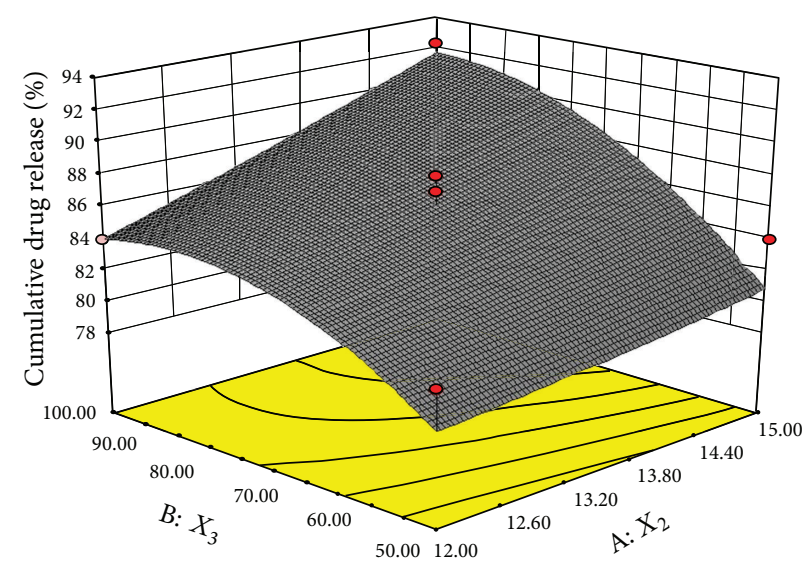

(c)

FIGURE 3: 3D-response surface plots for percentage of cumulative drug release as functions of two factors. 


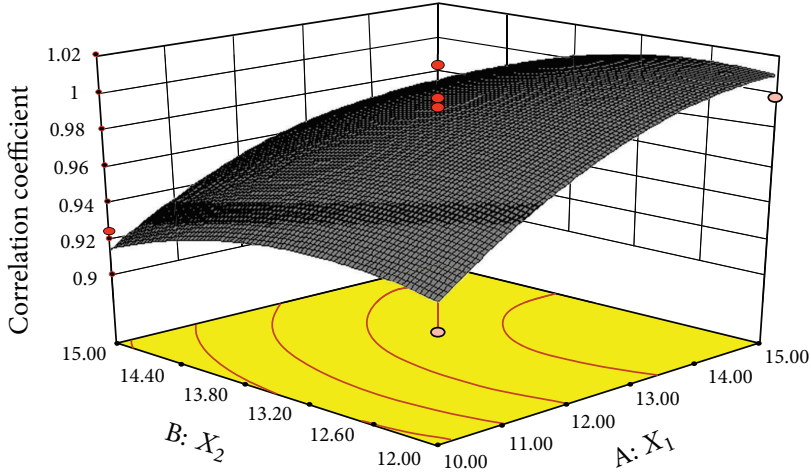

(a)

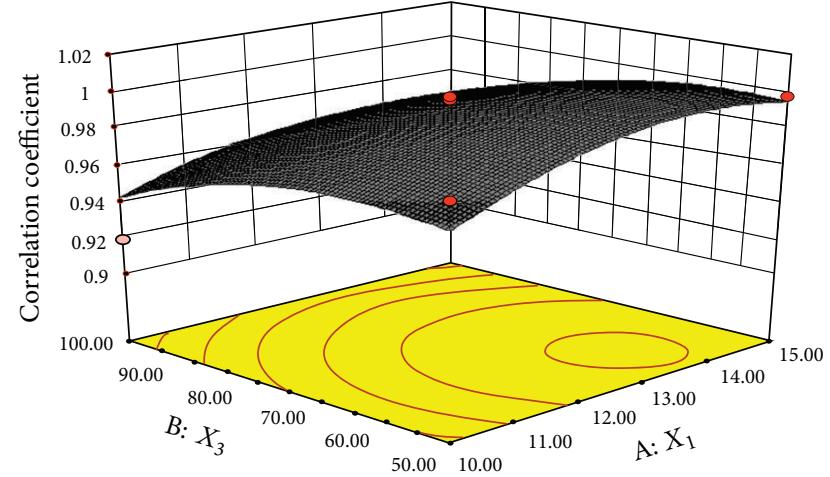

(b)

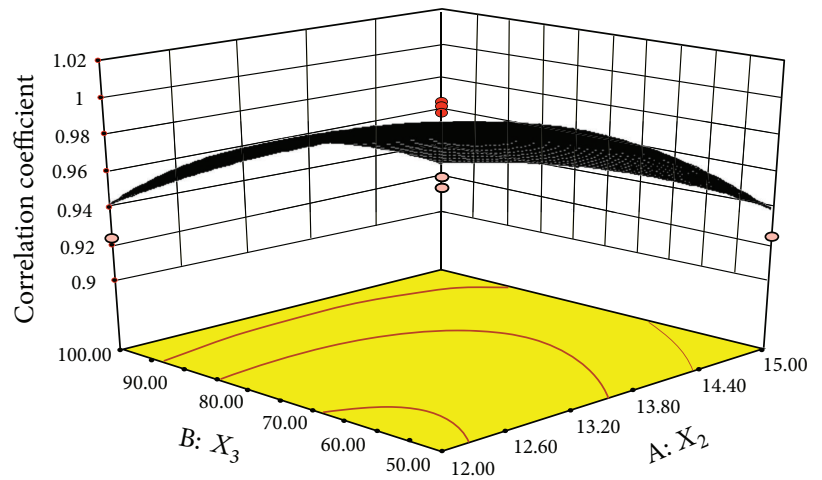

(c)

FIGURE 4: 3D-response surface plots for correlation coefficient as functions of two factors.

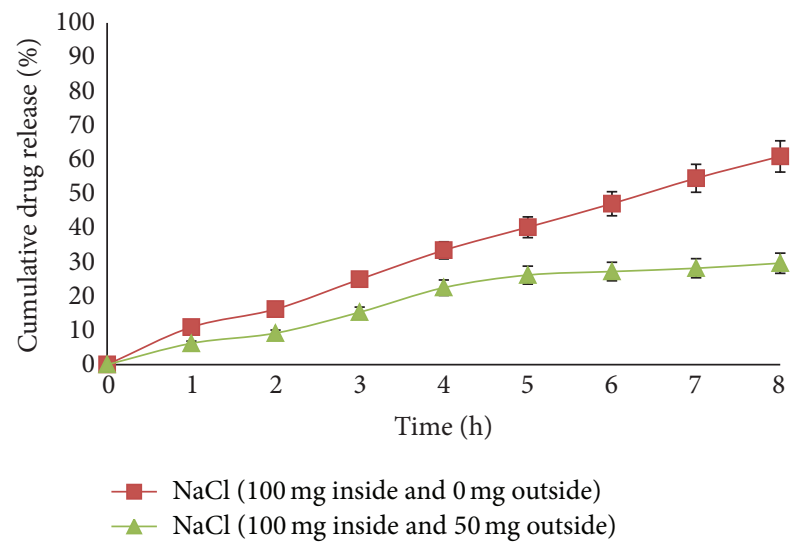

FIGURE 5: Comparative in vitro dissolution profiles showing effect of osmotic pressure.

composite design. The developed system was able to display complete drug delivery and zero-order release rate. Optimization studies proved that central composite design is efficient for understanding influence of formulation factors on the drug release behaviors. Results concluded that the release of optimized formulation $\left(\mathrm{F}_{18}\right)$ was dependent upon

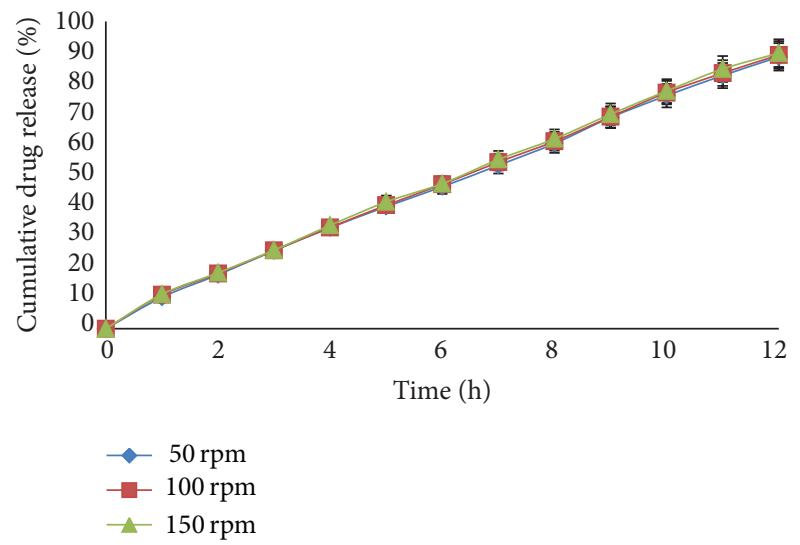

FIGURE 6: Dissolution profile of $\mathrm{F}_{18}$ showing effects of agitational intensity.

the osmotic pressure of dissolution medium while there was no effect of agitational intensity on the release of drug.

\section{Conflict of Interests}

The authors report no conflict of interests and have received no financial support for the present work. 


\section{Acknowledgment}

The authors thank Professor P. K. Khosla (Vice Chancellor of Shoolini University) for the perennial guidance, inspiration, and providing the facilities to complete this work.

\section{References}

[1] M. Marucci, G. Ragnarsson, and A. Axelsson, "Evaluation of osmotic effects on coated pellets using a mechanistic model," International Journal of Pharmaceutics, vol. 336, no. 1, pp. 6774, 2007.

[2] N. Özdemir and J. Şahin, "Design of a controlled release osmotic pump system of ibuprofen," International Journal of Pharmaceutics, vol. 158, no. 1, pp. 91-97, 1997.

[3] H. Gupta, D. Bhandari, and A. Sharma, "Recent trends in oral drug delivery: a review," Recent Patents on Drug Delivery and Formulation, vol. 3, no. 2, pp. 162-173, 2009.

[4] R. Gupta, P. Basniwal, and G. Rathore, "Osmotically controlled oral drug delivery systems: a review," International Journal of PharmTech Research, vol. 1, pp. 269-275, 2009.

[5] R. K. Verma, D. M. Krishna, and S. Garg, "Formulation aspects in the development of osmotically controlled oral drug delivery systems," Journal of Controlled Release, vol. 79, no. 1-3, pp. 7-27, 2002.

[6] C.-Y. Wang, H.-O. Ho, L.-H. Lin, Y.-K. Lin, and M.-T. Sheu, "Asymmetric membrane capsules for delivery of poorly watersoluble drugs by osmotic effects," International Journal of Pharmaceutics, vol. 297, no. 1-2, pp. 89-97, 2005.

[7] N. Jain, R. Sareen, and K. L. Dhar, "In-situ solubility modulation for osmotic flow of cefadroxil through asymmetric membrane capsules," RGUHS Journal of Pharmaceutical Sciences, vol. 2, no. 4, pp. 26-40, 2012.

[8] A. K. Philip and K. Pathak, "Wet process-induced phasetransited drug delivery system: a means for achieving osmotic, controlled, and level A IVIVC for poorly water-soluble drug," Drug Development and Industrial Pharmacy, vol. 34, no. 7, pp. 735-743, 2008.

[9] S. Agarwal and A. V. Rao, "Tomato lycopene and its role in human health and chronic diseases," Canadian Medical Association Journal, vol. 163, no. 6, pp. 739-744, 2000.

[10] W. Stahl and H. Sies, "Lycopene: a biologically important carotenoid for humans?" Archives of Biochemistry and Biophysics, vol. 336, no. 1, pp. 1-9, 1996.

[11] G. A. Rocha, C. S. Fávaro-Trindade, and C. R. F. Grosso, "Microencapsulation of lycopene by spray drying: characterization, stability and application of microcapsules," Food and Bioproducts Processing, vol. 90, no. 1, pp. 37-42, 2012.

[12] M. Vertzoni, T. Kartezini, C. Reppas, H. Archontaki, and G. Valsami, "Solubilization and quantification of lycopene in aqueous media in the form of cyclodextrin binary systems," International Journal of Pharmaceutics, vol. 309, no. 1-2, pp. 115122, 2006.

[13] A. K. Philip, K. Pathak, and P. Shakya, "Asymmetric membrane in membrane capsules: a means for achieving delayed and osmotic flow of cefadroxil," European Journal of Pharmaceutics and Biopharmaceutics, vol. 69, no. 2, pp. 658-666, 2008.

[14] E. Karavas, E. Georgarakis, M. P. Sigalas, K. Avgoustakis, and D. Bikiaris, "Investigation of the release mechanism of a sparingly water-soluble drug from solid dispersions in hydrophilic carriers based on physical state of drug, particle size distribution and drug-polymer interactions," European Journal of Pharmaceutics and Biopharmaceutics, vol. 66, no. 3, pp. 334-347, 2007.

[15] R. Sareen, N. Jain, and K. L. Dhar, "Development of colon specific microspheres of flurbiprofen for inflammatory bowel disease," Current Drug Delivery, vol. 10, no. 5, pp. 564-571, 2013.

[16] United State Pharmacopoeia, United State Pharmacopoeial Convention, Rockville, Md, USA, 2004. 

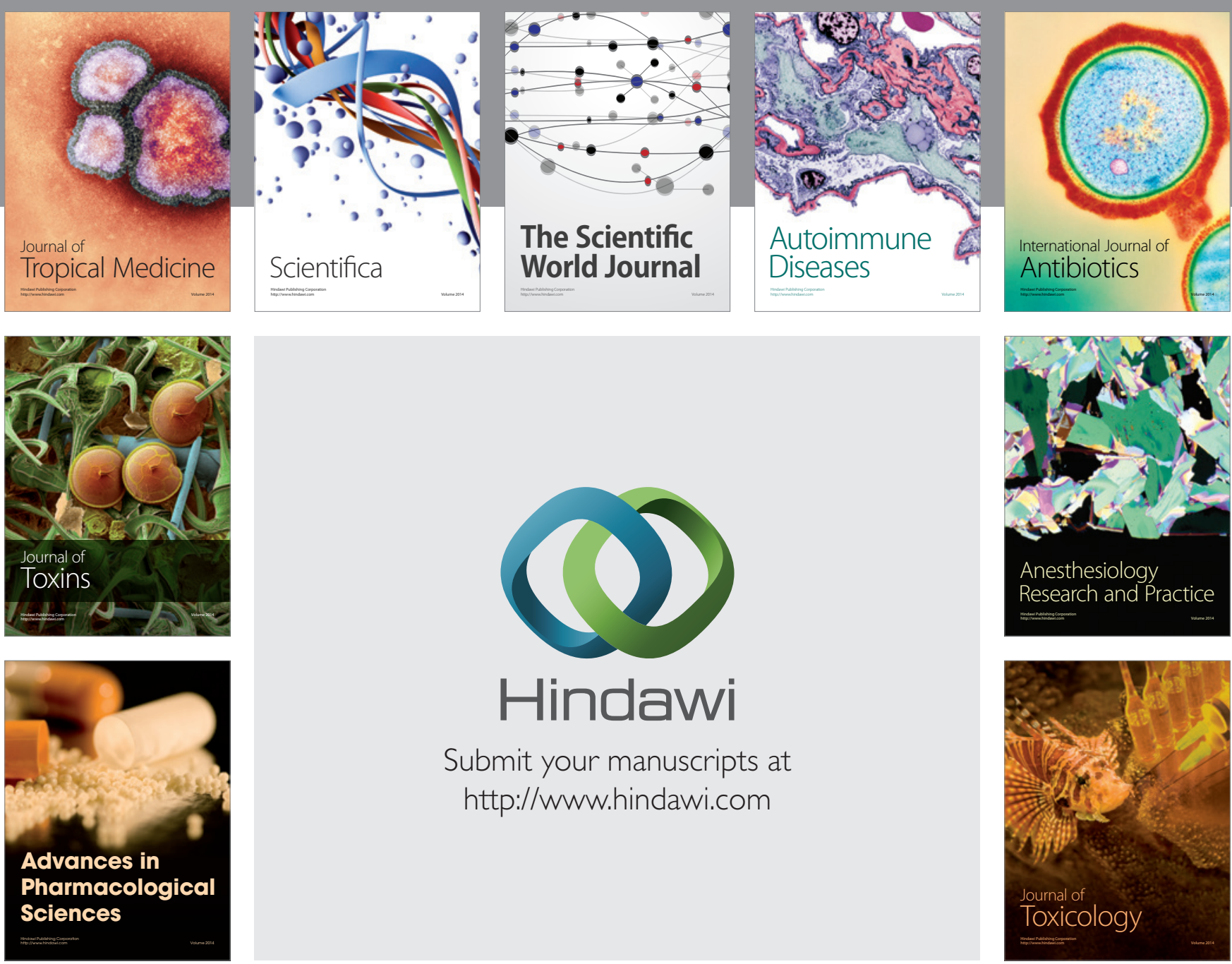

\section{Hindawi}

Submit your manuscripts at

http://www.hindawi.com
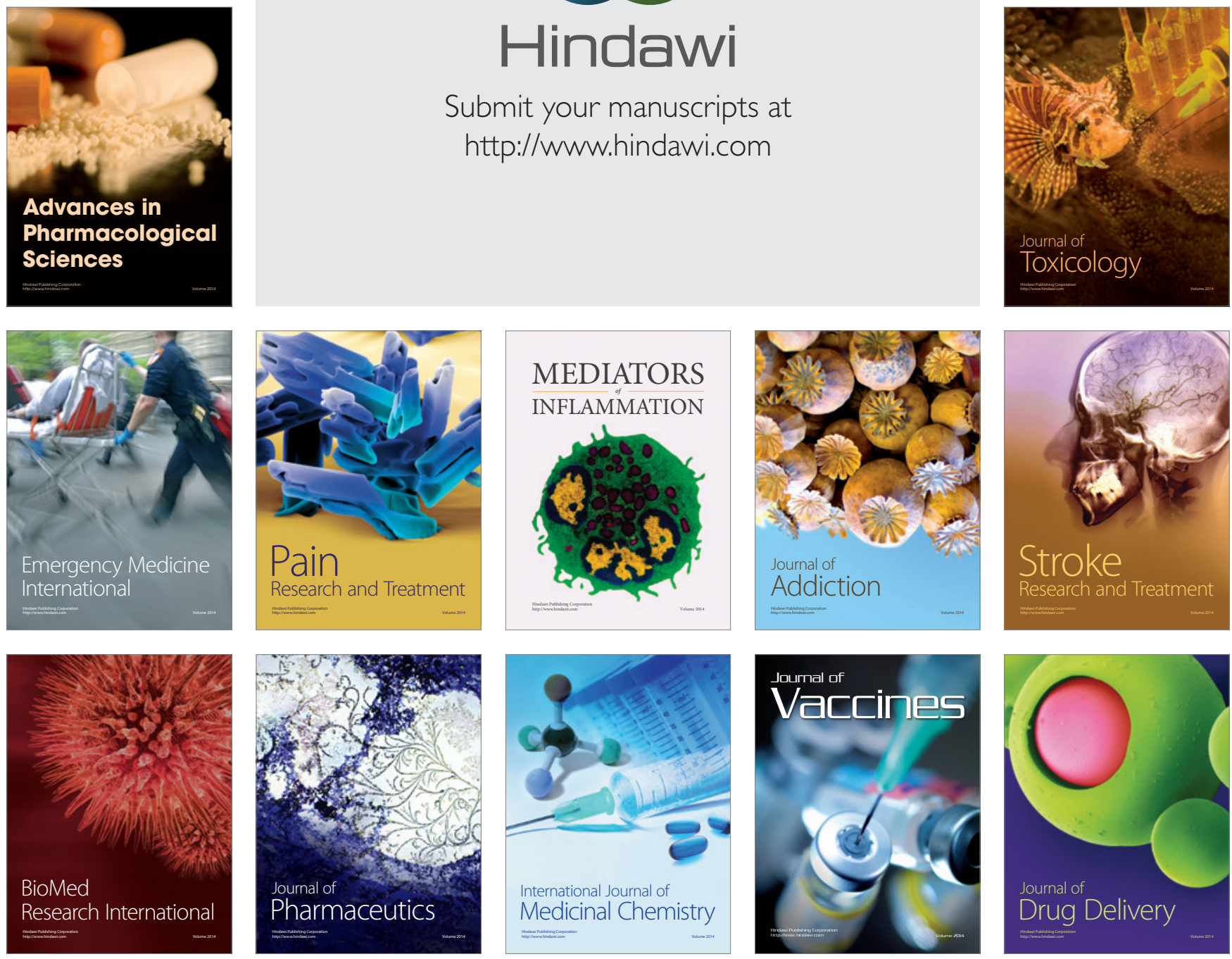